\title{
A comparison between single and composite milk samples for the genetic evaluation of milk composition in dairy cattle
}

\author{
R. van Dyk ${ }^{1}$, F.W.C. Neser ${ }^{1 \#}$ \& F.H. Kanfer ${ }^{2}$ \\ ${ }^{1}$ Department of Animal Science, University of the Free State, PO Box 339, Bloemfontein 9300, South Africa \\ ${ }^{2}$ Department of Statistics, University of Pretoria, Pretoria 0002, South Africa
}

\begin{abstract}
A simulation study was carried out to compare the use of single and composite milk samples for the evaluation of milk composition in dairy cattle. The genetic correlation between the two sampling methods was estimated. Results showed a high genetic correlation between the breeding values arrived from composite and single samples. This indicates that the same genes are possibly responsible for both traits, which makes it possible to use a single sample, instead of a composite sample, in predicting breeding values.
\end{abstract}

Keywords: butterfat, composite sample, dairy cattle evaluation, single sample

${ }^{\#}$ Corresponding author. E-mail: neserfw@sci.uovs.ac.za

\section{Introduction}

Milk recording entails measuring daily milk yield and composition. These measurements are used for herd management decisions as well as cow and sire evaluations in order to determine their genetic merit. It was first implemented in South Africa in 1917 by the then Friesian Breed Society and subsequently taken over by the State in 1919 (Grobler \& Loubser, 1983). The Milk Recording Scheme was managed entirely by the State and included on-farm tests to check that participants followed the correct sampling procedure. During 1975 it was decided to simplify the Scheme and allow farmers to participate more actively in the collection of multiple samples (morning and evening) which were sent to a central laboratory and analysed. Some errors did occur in the collection of the samples, but these were compensated for by what was thought to be a more accurate method of analysing in a central laboratory (Annual Report - ARC, 1996).

To make milk recording more user-friendly and cost effective the Management Committee of the Dairy Cattle Performance Testing Scheme replaced composite sampling with a single sample in 1995. The implementation of the new Scheme was based on the fact that there were practically no differences between the averages of two test years, the first year based on composite samples, the second year on single samples (National Dairy Cattle Performance Testing Scheme: South Africa's Annual Report, 1996). This comparison was, however, not scientifically validated since there was no data available to make a scientific evaluation and compare the differences. In order to compare the two sampling methods, both samples should be taken at the same time of the day. This clearly points to the problem of data collection, which can benefit from a single sampling procedure. A detailed description of the current milk-recording scheme in South Africa was reported by De Waal \& Heydenrych (2001) and Loubser (2001).

Total production in a 305-day lactation, as measured by the Milk Recording Scheme, is traditionally the trait under consideration when calculating breeding values. Using only single, either morning or afternoon, samples in the calculating of total 305-day production is clearly a different trait from actual total production. This raises the question whether the latter can be used in predicting breeding values for the first trait.

A simulation approach was followed to investigate this problem since no real data was available. The simulation is motivated also by factors such as comparisons between true and predicted genetic components, removal of artificial effects caused by non compliance to underlying assumptions such as selection, etc.

Several authors have investigated this problem. Most of them followed an approach in which 305-day yields were estimated from single milkings (Hargrove, 1994; Palmer et al., 1994; Cassandro et al., 1995; Schaeffer \& Jamrozik, 1996; Liu et al., 2000). The approach in this study was slightly different in that the effect of predicting breeding values directly from single milkings was considered. It was not the intention of the study to investigate the effect of alternating morning and evening (Am-Pm) milk recording procedures which seem to be the current preferred method of choice (Averdunk et al., 1998; Liu et al., 2000). Bias from taking only morning or afternoon samples can be reduced by alternating between morning and afternoon, therefore, benefiting any single milking procedure (Everett \& Wadel, 1969; Delorenzo \& Wiggans, 1986; Wangler et al., 1996; Aumann \& Duda, 1997). 


\section{Materials and methods}

To obtain information on the advantage and accuracy of having a composite, instead of a single sample, records are needed. Suitable records are scarce since the collection is extremely time consuming and costly. De Waal \& Heydenrich (2001) investigated the influence of sample frequency during milk recording on the reliability of performance testing in dairy cows. Single and composite samples were taken in four herds. A single sample was taken in the morning and evening at the same time as the two samples comprising the composite sample. Records were obtained for 236 cows. These observed differences between the single and composite samples were used in simulating random differences, which were then used to simulate single milkings from simulated composite samples. The composite samples were simulated as described by Van Dyk et al. (2001). A simple realistic herd was simulated with a pedigree structure, animal replacement policy, selection procedures, etc. Composite fat yield was simulated using the model:

$$
\mathrm{y}_{\mathrm{ij}}=\mathrm{f}_{\mathrm{i}}+\mathrm{a}_{\mathrm{ij}}+\mathrm{e}_{\mathrm{ij}}
$$

where $f_{i}$ represents the fixed effect at level $i$,

$\mathrm{a}_{\mathrm{ij}}$ represents the random genetic component animal $\mathrm{j}$ fixed effect $\mathrm{i}$,

$\mathrm{e}_{\mathrm{ij}}$ represents the random error component,

$\mathrm{y}_{\mathrm{ij}}$ represents butterfat.

The random genetic component $\left(\mathrm{a}_{\mathrm{ij}}\right)$ and the error component $\left(\mathrm{e}_{\mathrm{ij}}\right)$ are normally distributed with mean zero, variances $\sigma_{\mathrm{a}}^{2}$ and $\sigma_{\mathrm{e}}{ }^{2}$ respectively. The genetic and error components were statistically independent. The values for the variance components, $\sigma_{\mathrm{a}}{ }^{2}=293$ and $\sigma_{\mathrm{e}}{ }^{2}=534$, were obtained from du Toit et al. (1998). This implies a realistic heritability estimate of 0.35 .

Adding a random difference (as indicated above) to the composite sample simulated single samples, thus:

$$
y_{i j}=f_{i}+a_{i j}+d_{i j}+e_{i j}
$$

With the terms as defined above and $\mathrm{d}_{\mathrm{ij}}$ the random selected difference from the empirical distribution of differences. The random difference is assumed independent from all other random components. Multiple trait analyses were done using REML (Gillmore et al., 1999) procedures for all 25 simulation rounds to determine the (co)variance components and subsequent genetic correlation estimates between the single and composite samples.

\section{Results and discussion}

Tables 1 and 2 present the true fixed effect levels, mean estimated fixed effect levels as well as the $99 \%$ confidence interval for the true fixed effect levels. The estimates were for the 25 simulation rounds and for single and composite samples.

In the first four years an underestimation of the fixed effect in both traits occurred. No selection took place during this period and all animals were retained. After this period (year 5-20) an overestimation of the fixed effects occurred. This could be ascribed to the selection that took place during that period (Van Dyk et al., 2001) and not to the sampling method. It is interesting to note that there is virtually no difference between the estimated fixed effect levels of the two traits.

The error and total variance in the composite samples were higher than those obtained in the single samples. However, there was virtually no difference in the additive variance of the different sampling methods. The decrease in the error and total variance in the single sampling method could be a result of the simulation process. The error variance in the single sampling was underestimated and overestimated in the composite sample compared to the value used in the simulation process. The additive variance was totally underestimated in both cases. This could be attributed to the selection that took place in the population (Van Dyk et al., 2001).

The heritability estimate of the single sample is slightly higher than that of the composite sample. It is still, however, much lower than the simulated value. This could again be attributed to the selection in the population (Van Dyk et al., 2001). It should be noted that the true breeding value of an animal was used as basis for the simulation of the single and composite sample and this will explain the similarity of the additive 
variance between the different simulation rounds. In each case the genetic correlation between the two traits was estimated as close to unity.

Table 1 True fixed effect levels, average estimated fixed effect levels and $99 \%$ confidence interval for the true fixed effect level in kilogram (Composite sample)

\begin{tabular}{|c|c|c|c|c|}
\hline \multicolumn{5}{|c|}{ COMPOSITE SAMPLE } \\
\hline \multirow[b]{2}{*}{$\begin{array}{c}\text { Fixed effect } \\
\text { level }\end{array}$} & \multirow[b]{2}{*}{ Mean } & \multicolumn{2}{|c|}{$99 \%$ Confidence Interval } & \multirow[b]{2}{*}{ True level } \\
\hline & & Lower border & Upper border & \\
\hline 1 & 106.5 & 107.5 & 114.0 & 112.5 \\
\hline 2 & 118.4 & 122.8 & 124.6 & 125.0 \\
\hline 3 & 130.9 & 134.6 & 136.7 & 137.5 \\
\hline 4 & 143.8 & 148.4 & 147.5 & 150.0 \\
\hline 5 & 163.8 & 175.2 & 170.1 & 162.5 \\
\hline 6 & 179.1 & 188.4 & 187.5 & 175.0 \\
\hline 7 & 193.3 & 198.3 & 204.0 & 187.5 \\
\hline 8 & 206.2 & 217.0 & 215.3 & 200.0 \\
\hline 9 & 169.7 & 186.5 & 173.9 & 160.5 \\
\hline 10 & 165.2 & 180.8 & 172.9 & 156.0 \\
\hline 11 & 161.0 & 175.6 & 166.8 & 151.5 \\
\hline 12 & 157.0 & 169.5 & 162.6 & 147.0 \\
\hline 13 & 153.6 & 158.7 & 164.3 & 142.5 \\
\hline 14 & 148.1 & 157.0 & 159.0 & 138.0 \\
\hline 15 & 144.8 & 153.6 & 153.4 & 133.5 \\
\hline 16 & 139.7 & 145.8 & 146.5 & 129.0 \\
\hline 17 & 189.2 & 202.0 & 195.4 & 180.0 \\
\hline 18 & 199.2 & 208.1 & 206.8 & 190.0 \\
\hline 19 & 209.1 & 216.0 & 219.2 & 200.0 \\
\hline 20 & 218.7 & 223.0 & 233.9 & 210.0 \\
\hline
\end{tabular}

Table 2 True fixed effect levels, average estimated fixed effect levels and $99 \%$ confidence interval for the true fixed effect level in kilogram (Single sample)

\begin{tabular}{|c|c|c|c|c|}
\hline \multicolumn{5}{|c|}{ SINGLE SAMPLE } \\
\hline \multirow[b]{2}{*}{$\begin{array}{c}\text { Fixed effect } \\
\text { level }\end{array}$} & \multirow[b]{2}{*}{ Mean } & \multicolumn{2}{|c|}{ 99\% Confidence Interval } & \multirow[b]{2}{*}{ True level } \\
\hline & & Lower border & Upper border & \\
\hline 1 & 107.6 & 108.6 & 114.8 & 112.5 \\
\hline 2 & 119.8 & 123.6 & 125.6 & 125.0 \\
\hline 3 & 132.1 & 135.8 & 137.1 & 137.5 \\
\hline 4 & 145.0 & 148.9 & 148.8 & 150.0 \\
\hline 5 & 164.9 & 175.9 & 170.8 & 162.5 \\
\hline 6 & 180.1 & 189.4 & 187.9 & 175.0 \\
\hline 7 & 194.7 & 199.6 & 205.0 & 187.5 \\
\hline 8 & 207.6 & 218.1 & 215.5 & 200.0 \\
\hline 9 & 171.5 & 187.1 & 175.0 & 160.5 \\
\hline 10 & 167.1 & 182.0 & 174.0 & 156.0 \\
\hline 11 & 162.6 & 176.9 & 167.3 & 151.5 \\
\hline 12 & 158.9 & 170.7 & 163.4 & 147.0 \\
\hline 13 & 155.3 & 159.8 & 165.3 & 142.5 \\
\hline 14 & 149.4 & 158.1 & 160.2 & 138.0 \\
\hline 15 & 146.0 & 154.5 & 154.1 & 133.5 \\
\hline 16 & 141.6 & 146.9 & 147.0 & 129.0 \\
\hline 17 & 191.0 & 202.3 & 197.0 & 180.0 \\
\hline 18 & 200.8 & 209.5 & 207.8 & 190.0 \\
\hline 19 & 210.8 & 216.6 & 220.4 & 200.0 \\
\hline 20 & 219.4 & 223.6 & 234.3 & 210.0 \\
\hline
\end{tabular}


Variance component estimates for the single and composite samples are presented in Table 3.

Table 3 Estimated variance components for single and composite samples (bivariate analysis)

\begin{tabular}{|c|c|c|c|c|c|c|}
\hline $\begin{array}{l}\text { Simulation } \\
\text { Round }\end{array}$ & $\begin{array}{c}\text { Single } \\
\text { Sample } \\
\text { Additive } \\
\text { Variance } \\
\end{array}$ & $\begin{array}{c}\text { Single } \\
\text { sample } \\
\text { Error } \\
\text { Variance } \\
\end{array}$ & $\begin{array}{c}\text { Single } \\
\text { sample } \\
\text { Phenotypic } \\
\text { Variance } \\
\end{array}$ & $\begin{array}{l}\text { Composite } \\
\text { Sample } \\
\text { Additive } \\
\text { Variance } \\
\end{array}$ & $\begin{array}{l}\text { Composite } \\
\text { sample } \\
\text { Error } \\
\text { Variance } \\
\end{array}$ & $\begin{array}{c}\text { Composite } \\
\text { sample } \\
\text { Phenotypic } \\
\text { Variance } \\
\end{array}$ \\
\hline 1 & 78.88 & 528.60 & 607.48 & 80.49 & 557.00 & 637.49 \\
\hline 2 & 88.88 & 505.00 & 593.88 & 93.30 & 537.70 & 631.00 \\
\hline 3 & 63.95 & 528.50 & 592.45 & 64.10 & 557.60 & 621.70 \\
\hline 4 & 106.20 & 509.40 & 615.60 & 102.60 & 546.60 & 649.20 \\
\hline 5 & 114.60 & 491.10 & 605.70 & 119.30 & 521.40 & 640.70 \\
\hline 6 & 65.06 & 542.90 & 607.96 & 62.80 & 573.10 & 635.90 \\
\hline 7 & 95.94 & 514.40 & 610.34 & 96.74 & 546.40 & 643.14 \\
\hline 8 & 113.80 & 510.80 & 624.60 & 113.60 & 540.30 & 653.90 \\
\hline 9 & 73.14 & 524.80 & 597.94 & 72.76 & 560.50 & 633.26 \\
\hline 10 & 96.57 & 532.70 & 629.17 & 97.08 & 561.80 & 658.88 \\
\hline 11 & 68.54 & 523.80 & 592.30 & 59.45 & 566.80 & 626.25 \\
\hline 12 & 72.42 & 530.40 & 602.82 & 72.93 & 571.00 & 643.93 \\
\hline 13 & 61.62 & 535.00 & 596.62 & 60.13 & 574.30 & 634.43 \\
\hline 14 & 101.90 & 504.70 & 606.60 & 108.00 & 532.60 & 640.60 \\
\hline 15 & 60.40 & 534.90 & 595.30 & 60.90 & 562.20 & 623.10 \\
\hline 16 & 118.20 & 500.90 & 619.10 & 128.40 & 525.80 & 654.20 \\
\hline 17 & 94.07 & 500.90 & 594.97 & 92.15 & 536.90 & 628.05 \\
\hline 18 & 133.30 & 479.20 & 612.50 & 126.30 & 516.60 & 642.90 \\
\hline 19 & 76.00 & 537.80 & 613.80 & 72.79 & 574.00 & 646.79 \\
\hline 20 & 59.86 & 535.30 & 595.16 & 54.81 & 571.80 & 626.61 \\
\hline 21 & 53.51 & 553.60 & 607.11 & 54.82 & 589.80 & 644.62 \\
\hline 22 & 52.87 & 551.30 & 604.17 & 49.29 & 595.10 & 644.39 \\
\hline 23 & 104.80 & 523.90 & 628.70 & 104.30 & 565.00 & 669.30 \\
\hline 24 & 80.84 & 539.80 & 620.64 & 80.46 & 572.90 & 653.36 \\
\hline 25 & 62.21 & 536.60 & 598.81 & 58.32 & 575.40 & 633.80 \\
\hline Mean & 83.90 & 523.05 & 606.95 & 83.43 & 557.30 & 640.70 \\
\hline
\end{tabular}

The heritability estimate of the two sampling methods as well as the genetic correlation estimates between the two methods are presented in Table 4.

\section{Conclusion}

The results from this study showed that a near perfect positive genetic correlation exists between the single and composite samples. This indicates that the same genes are possibly responsible for both the single and composite samples and could, therefore, be considered to be the same trait. This study indicated the possibility of using single samples instead of composite samples in calculating breeding values for dairy cattle. Further research, using real data, is still required. The possibility of using an alternating sampling procedure should also be investigated. 
Table 4 The heritability- and genetic correlation estimates between the different sampling methods

\begin{tabular}{crrr}
\hline Simulation round & Heritability-single sample & Heritability composite sample & Genetic correlation \\
\hline 1 & 12.99 & 12.63 & 99.76 \\
2 & 14.97 & 14.78 & 99.90 \\
3 & 10.79 & 10.31 & 99.86 \\
4 & 17.25 & 15.81 & 99.99 \\
5 & 18.92 & 18.62 & 99.93 \\
6 & 10.70 & 9.88 & 99.75 \\
7 & 15.72 & 15.04 & 99.97 \\
8 & 18.21 & 17.37 & 99.97 \\
9 & 12.23 & 11.49 & 99.95 \\
10 & 15.34 & 14.73 & 99.95 \\
11 & 11.57 & 9.49 & 99.33 \\
12 & 12.01 & 11.32 & 99.86 \\
13 & 10.33 & 9.48 & 99.16 \\
14 & 16.80 & 16.86 & 99.78 \\
15 & 10.15 & 9.77 & 99.97 \\
16 & 19.09 & 19.62 & 99.92 \\
17 & 15.81 & 14.65 & 99.94 \\
18 & 21.76 & 19.65 & 99.93 \\
19 & 12.38 & 11.25 & 99.91 \\
20 & 10.06 & 8.75 & 99.32 \\
21 & 8.81 & 8.50 & 99.18 \\
22 & 8.75 & 7.65 & 99.33 \\
23 & 16.67 & 15.58 & 99.92 \\
24 & 13.03 & 12.32 & 99.40 \\
25 & 10.39 & 9.20 & 99.96 \\
Mean & 13.79 & 12.99 & 99.76 \\
\hline
\end{tabular}

\section{References}

Annual Report, 1996. National Dairy Cattle Performance Testing Scheme: South Africa. Agricultural Research Council, Irene, South Africa.

Aumann, J. \& Duda, J., 1997. Reliability of new methods in milk recording. $48^{\text {th }}$ Annual Meeting of the EAAP, Wein Paper C5.7.

Averdunk, G., Aumann, J. \& Duda, J., 1998. Performance recording of animals, state of the art: Tendencies in $\mathrm{Am} / \mathrm{Pm}$ recording in Germany and non-conventional recording methods in the future, Proc. $31^{\text {st }}$ Biennial Session of ICAR, Rotorua, New Zealand. 139 pp.

Cassandro, M., Carnier, P., Gallo, L., Mantovani, R., Contiero, B., Bittane, G. \& Jansen, G.B., 1995. Bias and accuracy of single milk testing schemes to estimate daily and lactation milk yield. J. Dairy Sci. 78, 2884-2893.

DeLorenzo, M.A. \& Wiggans, G.R., 1986. Factors for estimating daily yield of milk, fat and protein from a single milking for herds milked twice a day. J. Dairy Sci. 69, 2386-2394.

De Waal, H. \& Heydenrych, H.J., 2001. The effect of sampling frequency on the accuracy of estimates of milk-fat yields of dairy cows. S. Afr. J. Anim. Sci. 31, 9-11.

Du Toit, J., van Wyk, J.B., \& van der Westhuizen, J., 1998. Genetic parameter estimates in the South African Jersey Breed. S. Afr. J. Anim. Sci. 28, 146-152.

Everett, R.W. \& Wadell, L.H., 1970. Sources of variation affecting ratio factors for estimating total daily yield from individual milkings. J. Dairy Sci. 53, 1430-1435.

Gillmore, A.R., Cullis, B.R., Welham, S.J. \& Thompson, R., 2000. ASREML Reference Manual.

Grobler, B.R. \& Loubser, L.F.B., 1983. Die ontwikkeling van melkprestasie toetsing in die RSA. Nasionale Melkprestasie-en-Nageslag Toetsskema. Jaarverslag: pp. 3-6.

Hargrove, G.L., 1994. Bias in composite milk samples with unequal milking intervals. J. Dairy Sci. 77, 19171921.

Jamrozik, J., Schaeffer, L.R. \& Dekkers, J.C.M., 1997. Genetic evaluation of dairy cattle using test day 
yields and Random Regression Model. J. Dairy Sci. 80, 1217-1226.

Loubser, L.F.B., 2001. National Dairy Animal Improvement Testing Scheme. Dairy Herd Improvement in South Africa. Eds. Loubser, L.F.B., Banga, C.B., Scholtz, M.M. \& Hallowell, G.J., ARC Animal Improvement Institute, Irene, pp. 7-14.

Liu, Z, Reents, R., Reinhardt, F. \& Kuwan, K., 2000. Approaches to estimating daily yield from single milk testing schemes and use of am-pm records in Test-day model genetic evaluation in dairy cattle. J. Dairy Sci. 83, 2672-2682.

Palmer, R.W., Jensen, E.L. \& Hardie, A.R., 1994. Removal of within-cow differences between morning and evening milk yields. J. Dairy Sci. 77, 2663-2670.

Shaeffer, L.R \& Jamrozik, J., 1996. Multi-trait prediction of lactation yields for dairy cows. J. Dairy Sci. 79, 2044-2055.

Van Dyk, R. Neser, F.W.C. \& Kanfer, F.H., 2001. The effect of selection on genetic parameter estimates. S. Afr. J. Anim. Sci. 31, 107-104.

Wangler, A., Weiher, O. \& Wolf, J., 1996. Einmal alle vier Wochen. Der Tierzüchter. 3, 22-24. 